\title{
THE UK ECONOMY IN THE LONG EXPANSION AND ITS AFTERMATH
}

\section{Jagjit S. Chadha Alec Chrystal* Joe Pearlman** Peter N. Smith*** Stephen Wright ${ }^{* * * *}$}

* Cass Business School

**City University London

$* * *$ University of York

$* * * *$ Birkbeck, University of London

NIESR Discussion Paper No. 473

Date: 20 October 2016 


\section{About the National Institute of Economic and Social Research}

The National Institute of Economic and Social Research is Britain's longest established independent research institute, founded in 1938. The vision of our founders was to carry out research to improve understanding of the economic and social forces that affect people's lives, and the ways in which policy can bring about change. Seventy-five years later, this remains central to NIESR's ethos. We continue to apply our expertise in both quantitative and qualitative methods and our understanding of economic and social issues to current debates and to influence policy. The Institute is independent of all party political interests.

National Institute of Economic and Social Research

2 Dean Trench St

London SW1P 3HE

T: +44 (0)20 72227665

E: enquiries@niesr.ac.uk

niesr.ac.uk

Registered charity no. 306083

This paper was first published in October 2016

(c) National Institute of Economic and Social Research 2016 


\section{The UK Economy in the Long Expansion and its Aftermath Jagjit S. Chadha, Alec Chrystal, Joe Pearlman, Peter N. Smith and Stephen Wright}

\section{Abstract}

In the aftermath of the inflation and recessions of the 1970s and early 1980s, from the early 1990s onwards there was a major upswing in most advanced countries. In the UK it was the longest period of economic expansion on record. But it came to an abrupt end in 2007, with the freezing of the interbank markets and the collapse of Northern Rock, followed in 2008 by Bear Stearns and Lehman Brothers.

Before the crisis, many economists had begun to call this period of upswing the Great Moderation; and, echoing developments in other disciplines such as political thought, some openly wondered whether we had found the answer to the questions that had perennially been posed by "boom and bust". But given the magnitude of the shocks that hit the global economy in the crisis period of 2007-8 (and since then in a number of countries) the apparent reduction in macroeconomic volatility of the earlier period now appears, with the benefit of hindsight, to have been largely illusory. We therefore argue that the period 1992-2007 can more accurately (and less ambitiously) described as the Long Expansion - hence the title of this volume.

\section{Contact details}

Jagjit S. Chadha (j.chadha@niesr.ac.uk), National Institute of Economic and Social Research, 2 Dean Trench Street, London SW1P 3HE 


\section{Editors' Introduction}

In the aftermath of the inflation and recessions of the 1970s and early 1980s, from the early 1990s onwards there was a major upswing in most advanced countries. In the UK it was the longest period of economic expansion on record. But it came to an abrupt end in 2007, with the freezing of the interbank markets and the collapse of Northern Rock, followed in 2008 by Bear Stearns and Lehman Brothers.

Before the crisis, many economists had begun to call this period of upswing the Great Moderation; and, echoing developments in other disciplines such as political thought, some openly wondered whether we had found the answer to the questions that had perennially been posed by "boom and bust". But given the magnitude of the shocks that hit the global economy in the crisis period of 2007-8 (and since then in a number of countries) the apparent reduction in macroeconomic volatility of the earlier period now appears, with the benefit of hindsight, to have been largely illusory. We therefore argue that the period 1992-2007 can more accurately (and less ambitiously) described as the Long Expansion - hence the title of this volume.

It is now clear that many of the problems that have occupied policymakers during the global financial crisis were being incubated during this period. And so with the twin aims of encouraging more policy-focussed research on the UK, and to encourage policy debate, in the aftermath of the financial crisis and the prolonged economic recession, we commissioned ten papers from leading UK-based researchers to look at the issues that arose during the Long Expansion and its aftermath.

The chapters in this collected volume originate in papers presented at a conference held at Clare College, Cambridge on 19-23 September, 2013. ${ }^{1}$ The papers have been peer-reviewed and thoroughly revised since the initial versions presented at the conference. They offer a comprehensive overview of the UK economy over this period in a form that we hope will offer an authoritative and enduring perspective on the British economy in the early years of the $21^{\text {st }}$ century. We are grateful to the Bank of England, the INET Fund, and the Money, Macro, Finance Group for support in hosting this conference. We thank Chris Harrison and Phil Good for sponsoring the modern macroeconomic policymaking series, published by Cambridge University Press. Finally, we thank Jagjit Chadha for his support in organising and thinking of this conference and book.

\footnotetext{
${ }^{1}$ The papers and previous three conference can be viewed at: http://www.econ.cam.ac.uk/MMPM/.
} 
The volume opens with "Prospects for UK growth in the aftermath of the financial crisis", by Nicholas Oulton (London School of Economics). This paper starts by documenting the remarkable performance of the UK economy during the period 1990-2007 - the "Long Expansion" ${ }^{2}$ of the title of this book. By any standards - but particularly relative to what came before (and afterwards) productivity performance of the UK economy during this period was excellent, and looked set to continue. On the basis of pre-crisis data, using a two-sector growth model, Oulton argues that a plausible projection of the future growth rate of GDP per hour in the market sector would have been around $2 \frac{1}{2} \%$ p.a.

However, since the onset of the financial crisis and the Great Recession in the UK in Spring 200 such an optimistic projection has looked increasingly unlikely to be fulfilled. At the time when the paper was finalised (in early 2014) both GDP and GDP per hour had fallen, and the latter was still below the level reached at the peak of the boom. The paper shows that this fall in productivity was pervasive throughout a broad range of sectors of the UK economy. In the rest of the paper Oulton investigates competing explanations for how this can have occurred, and then reflects on the implications for the future.

The paper examines a wide range of hypotheses that have been proposed as an explanation of the productivity collapse: sectoral shifts; mis-measurement of banking output ; overheating during the boom (with consequent overstatement of potential output); lower inputs of both physical and/or human capital input; hoarding of labour and capital; so-called "zombie firms"; ${ }^{3}$ and fiscal austerity (the impact of which Oulton concludes has been overstated). Indeed the common feature of each of these explanations, Oulton concludes, is that none of them work: the productivity collapse remains, at the time of writing, a puzzle.

In considering future prospects the paper considers the likely impact of the financial crisis and the "Great Recession". Will its impact be entirely transitory? (i.e., with productivity reverting to its previous trend). Or permanent in terms of the level of productivity? Or (in the worst case scenario) permanent both in its impact on the level and growth rate of productivity? To address this question, Oulton uses a cross-country panel dataset of 61 countries over 1950-2010 to attempt to estimate the impact of financial crises, particularly banking crises, on productivity, capital, TFP and employment. He argues that banking crises generally have a long run impact on the level of productivity but not necessarily on its long run growth rate. He estimates that the permanent impact on the level of GDP per worker resulting from the crisis could be a substantial reduction of around $5 \frac{1}{2} \%$. But, more positively, the UK can eventually be expected to return to the growth rate that would have been predicted prior to the crisis.

Oulton cautions, however, that this (relatively optimistic) prediction is conditional on the UK continuing to follow good policies in other respects, in particular not allowing the ratio of government debt to GDP to rise excessively (the final chapter of this volume, by Paul Johnson, deals with this issue in considerably more depth).

Chapter 2, "Labor Market and Monetary Policy Reforms in the UK: a

\footnotetext{
${ }^{2}$ With thanks to Jagjit Chadha for this phrase to describe the period from the early 1990s to the Great financial crash.

3 This popular term has come to refer to firms that are just about able to meet their debt obligations to banks but are not investing.
} 
Structural Interpretation of the Implications", by Francesco Zanetti (Oxford), examines the sources of the stability both of the growth rate of the UK, and of the macro environment more generally, during the Long Expansion. Compared to the 1970s and 1980s. GDP and inflation were less volatile, and the level of inflation decreased markedly. Zanetti identifies two possible causes: first, the labour market reforms under Mrs Thatcher, which both weakened union power and reduced the replacement ratio of unemployment benefits, and second, the use of an explicit inflation target as a nominal anchor since 1992, which culminated in a new statutory framework for price stability in the form of the Bank of England Act in 1998. He attempts to assess the impact of these changes by posing two counter-factual questions: Would the introduction of these policy changes have produced a similarly favourable economic outlook if they had been accomplished in the earlier decades? And, if so, to what extent, if at all, might each of these two changes have played a role?

To assess this, using data from the earlier period 1971-1991, he estimates (and for some parameters calibrates) a New Keynesian model with optimizing behaviour by households and firms, where firms face a cost of adjusting nominal prices, and the labour market is characterized by search frictions and job-matching. The model also incorporates a central bank that conducts policy with a Taylortype rule by setting the nominal interest rate in reaction to deviations of inflation from its target and output from its long-run equilibrium. Unlike the explicit inflation targeting framework introduced in 1992 , where the target of inflation is constant, during the 1970s and 1980s, monetary policy can be represented by a time-varying inflation target which changed in reaction to exogenous disturbances. In contrast, from 1992 onwards, it is assumed that the inflation target was constant, with an increased weight assigned to inflation for the monetary policy objective.

Since it is the deep preference and structural parameters, as well as the policy parameters that are estimated, the model is intended to be immune to the Lucas critique, and thus is used to draw inferences about counterfactual scenarios. These examine whether the labour market reforms and changes to the monetary policy framework would have changed the economic outlook if they had been introduced in the earlier period. Utilising these policies in the estimated model suggest that labour market reforms would have eased the transition to lower inflation for most but not all of the period, via its impact on the real wage, and hence marginal cost. But the impact is very small: the counterfactual inflation rate never reduces by more than $1 / 2 \%$. At the same time the volatility of inflation and output growth significantly increases, so that the effects of changes in the monetary policy framework would have been mixed. A stronger reaction to inflation deviations from target would have lowered the volatility of inflation and output growth, but the introduction of a constant inflation target or a monetary policy that reacted strongly to output fluctuations would have increased volatility, so that the net effect is virtually unchanged. A potential conclusion to be drawn from these results is that the economy was simply inherently more volatile in the 70 s and at least the early 80 s, and thus that there may have been little scope for stabilization policy to improve matters.

In the next chapter, "Property Income and the Balance of Payments", by Tomas Key, Varun Paul, Martin Weale and Tomasz Wieladek (Bank of England), the authors explore another puzzling feature of the Long Expansion: how the United Kingdom was able, despite a current account trade deficit and apparent net external liabilities, both to earn a positive balance of net income from abroad almost every year and to improve its net external position during the Long Expansion. The puzzle is that the current account deficit, particularly in the 10 years leading up to the financial crisis does not 
square with the stability of net external assets over that period, unless there were higher systematic capital gains on the UK's assets compared with its liabilities. Indeed, between 1997 and 2012 the UK seems to have earned a total of capital gains or unidentified income worth nearly 20 per cent of 2012 GDP despite the fact that its net asset position is shown as a debtor.

The authors carefully analyse this question by exploiting a recently constructed dataset on capital gains and asset returns. Earlier studies had suggested that the composition of UK assets as compared with liabilities is biased towards high-yielding asset classes (the composition effect). In contrast, the authors' new dataset shows that the UK, like the US, enjoyed favourable returns on investment categories that were broadly similar for assets and liabilities. The authors note that the data do not reveal whether investors in UK foreign assets are more skilled than those investing in the UK, or whether they merely run greater risks.

This result motivates a study of the factors that may have led to this favourable position, and in particular whether the net income balance was influenced by changes in the regulatory environment. It is possible that the attractiveness of a country to foreign investors depends on the extent to which markets are regulated. In addition the United Kingdom's capacity to borrow more cheaply than it lends, might be a function of regulation. The authors study this possibility using a Bayesian Panel VAR for 13 OECD economies, which evaluates the interaction between consumption growth, inflation, the interest rate, net foreign income and the exchange rate, and allows for parameters that depend on the regulatory environment. This builds on earlier work which has shown that the way in which countries respond to shocks depends on their regulatory structure. The latter is measured using indices that represent exchange rate flexibility and financial, labour and product market deregulation. The panel approach has the usual advantage that there is more variation in the data, which makes it possible to determine the effects of regulatory changes with greater statistical significance. The Bayesian approach that is used for estimation is fairly novel in macroeconomics, and allows for the estimation of Bayesian shrinkage - the weight put on the prior covariance matrices of the time-varying parameters, which direct whether the econometrician puts more weight on the model structure or more weight on the data.

The results show that a substantial component of the improvement in the net income flow between the early 1990s and the middle of the next decade appears to have been a consequence of regulatory changes. In particular, the improvements due to financial regulation appear positive, while those due to product market regulation are negative. However, further analysis using the steady state of the VAR leads the authors to caution against accepting these results without more careful consideration. While the substantial offsetting effects from product market regulation and financial market regulation may be explained by the former having encouraged foreign investment in the UK, leading to an outflow of income, and the latter having benefited the growth of a financial sector that can earn more from foreign investments than the cost of finance, the authors note that it is more difficult to understand why labour market deregulation should lead to increased steady state income. They suggest that while the regulatory environment may have been beneficial, the upward trend of the regulatory variables may have led to an overstatement of their effects.

Given the prominence of the financial crisis at the onset of the recession that brought the Long Expansion to a dramatic close, the organisers of the conference were particularly keen to see 
research into the financial sector, both during the expansionary phase, and in the downturn that followed. The next three chapters all address the role of the financial sector, money and credit in the long expansion and the subsequent crisis, albeit with quite distinct emphases.

In Chapter 4, "UK broad money growth in the long expansion 1992-2007: what can it tell us about the role of money?" Michael McLeay and Ryland Thomas (Bank of England) subdivide their investigation of the role of money into three parts. The first is a survey of the literature that covers many different approaches to the role of monetary aggregates in the economy, together with an overview of broad trends. The authors show that money and credit both grew faster than nominal GDP throughout the long expansion (and during the decade before) and that credit grew faster than money. The second part of the chapter reports the results of the estimation of a long-run structural vector autoregression (SVAR) model and decomposition of factors driving money, lending, GDP and inflation. The SVAR is estimated using quarterly data over a long period (1967-2012) which includes both the Long Expansion and the onset of the crisis and the Great Recession. It uses a decomposition of predictive errors into structural shocks to aggregate demand, aggregate supply and monetary policy, but with the key addition of shocks arising from the banking system. These are the cost of intermediation, the cost and availability of wholesale funding, and a variable to capture bank risk taking. They also try to identify a risk-premium shock that originates in the non-bank financial sector. The estimation strategy both identifies the shocks and distinguishes between those that have permanent and temporary effects.

The impact of the standard shocks is much as would be expected. Demand shocks, for example, move output and inflation in the same direction, while supply shocks move them in opposite directions. As for the banking shocks, the cost of intermediation shock has effects on money, credit and asset prices but no significant effect on real activity. In contrast, the wholesale funding shock has effects on credit spreads and lending and this in turn does affect real activity. The bank risktaking shock affects money, credit and asset prices temporarily, but has no real effect on output in the long run (by assumption).

The authors find that over their long sample, supply shocks appear to play a bigger role in driving GDP than demand shocks, in contrast to traditional macroeconomic models which have tended to put most emphasis on demand shocks. This finding may be a product of the identifying assumptions used to distinguish demand and supply shocks, but it does add support to something closer to a real business cycle approach, where technology shocks are key drives of fluctuations, as opposed to more Keynesian approaches where aggregate demand shocks are the main source of volatility. They also provide an interesting insight into the financial crisis of 2007, which they find was preceded by credit growth originating from wholesale funding of the banking system. This result is consistent with stories about the global savings glut, the narrowing of risk premia on a wide class of assets and the "ferocious search for yield" that helped drive the credit and housing bubble prior to the US subprime crisis. In effect, the UK banks' 'customer funding gap' was filled by an abundance of funds channelled through the wholesale interbank market, much of which originated overseas. These flows rapidly reversed when the interbank markets froze in 2007/8 with the onset of the financial crisis.

In the third part of the chapter, the authors estimate a model of disaggregated money holdings for three specific sectors. These sectors are: other financial corporations (OFCs), proxied by insurance 
companies and pensions funds; private non-financial corporations (PNFCs); and households. The model is estimated for the period 1987-2008 on quarterly data. Key results are that the money growth in the OFCs sector from 2005 was linked to around 25\% of the build-up in asset prices, which in turn boosted consumer spending; while the growth of money within PNFCs is sufficient to explain business investment. The authors estimate that the combined impact of these two effects added around 3\% to GDP in 2005-7. In contrast, household money holding had little further informational content at this time.

The following Chapter, "An Old Fashioned Banking Crisis: Credit Growth and Loan Losses in the UK 1997-2012" by Alistair Milne and Justine Wood (University of Loughborough), examines the origins of the financial crisis in the banking sector, focussing on the expansion of credit in the UK over the years 1997-2007 and the subsequent loan losses on UK sterling lending.

The authors provide evidence of a substantial credit expansion, especially in lending secured on property. Yet they show that this led to only relatively modest losses for UK banks on residential mortgage lending in the crisis period of 2008-2013. Instead most losses on UK bank sterling lending were associated with commercial property lending. The authors consider parallels with the two previous episodes of large scale UK loan losses in 1973-75 and 1991-1993, both of which they revisit, and draw out similarities between the most recent banking crisis and these earlier events.

The chapter also consider the role of 'shadow' banking in this boom and bust. The authors introduce a careful distinction between 'old' and "new" shadow banking. The former takes funds from the established banking system, while 'new' shadow banking, uses the modern tools of securitisation and credit risk transfer in order to create money-like substitutes for traditional bank deposits and hence disintermediate entirely from the established banks. The authors find that, in contrast to the pattern in the United States, "new" shadow banking played only a minor role in the UK credit expansion. There was some 'old' shadow banking, with real estate investment trusts and other specialised real estate funds investing in commercial property. Securitisation of residential mortgages also helped fund what now, with hindsight, appears as an unwise extension of credit into other more risky areas of lending, notably commercial property. Otherwise, the authors conclude, this was a very old-fashioned banking crisis.

The third chapter focussing on the financial sector, "Household debt and spending in the United Kingdom" by Philip Bunn and May Rostom (Bank of England), examines another aspect of the buildup to the crisis. It is commonly thought (rightly or wrongly) that household debt played an important role in the boom and bust of the 2007-8 financial crisis. The authors of this chapter examine this question with evidence from a panel study using household level data drawn from the ONS Living Costs and Food Survey (LCF), which covers a sample of 6000 households on a regular basis. The data include detailed information for each household on income, spending (disaggregated by types of goods and services purchased) and debt.

The focus of this study is entirely on the influence of secured mortgage debt (which is over 80 per cent of the total debt) on spending pattern variations across different households and over time. Mortgage debt is clearly always linked to house purchase, but there is no evidence available in this data about the role of housing net worth. There is however some presumption that households with high debt to income ratios will also have a high debt to wealth ratio.

The authors find evidence to show that the build-up of mortgage debt prior to the financial crisis was (unsurprisingly) linked to house price rises. However, the focus of the paper is mainly on the extent to which high levels of secured debt affected household spending patterns. They find that 
higher debt households had higher consumer spending in the run up to the 2007 crisis, and that these same households cut back spending more sharply once the crisis broke. However, while statistically significant, these effects were not substantial and provide only a small part of the explanation of consumer spending trends in general.

Three hypotheses are posed as to why high-debt households cut back more than others after the crisis: first, that high debt restricted borrowers' access to future credit; second, that high debt may have raised worries about ability to make future interest payments ; third, households with high debts may have made larger adjustments to expectations of future income. The authors conclude that the data provide some support the first two of these explanations but not the third.

The implication of these results is that high levels of secured debt made consumer spending more volatile over the business cycle, as those with high debt tended to spend more during the upturn but also cut back more during the downturn. The authors conclude that policy makers responsible for financial and macro stability should, therefore, be concerned to ensure that debt levels do not become too high and too widespread in the household sector.

The period of the long expansion overlaps with that of the operational control of monetary policy in the UK passing to the Bank of England through the decisions of the Monetary Policy Committee (MPC). Since 1997 interest rate setting and, more recently, non-traditional monetary policy actions in pursuit of inflation stabilisation have been carried out by this group independently of the government of the day. The Long Expansion also saw considerable stability in inflation around its target level. The next two chapters of the volume examine the activities of the MPC over this period, from two quite distinct angles; while the following chapter considers the impact of global developments on UK inflation

\section{Chapter 7, "MPC Decision Making, the Long Expansion and the Crisis: Integration with the Global} Economy, Heterogeneity and Network Dynamics", by Arnab Bhattacharjee (Heriot-Watt University) and Sean Holly (University of Cambridge), examines the conduct of monetary policy through the voting records of individual members of the MPC over the period of the long expansion and the financial crisis. The authors estimate a model of MPC decision making that allows for heterogeneity and network interactions amongst members, using a panel dataset that includes both voting records and a range of macroeconomic indicators. The authors use their estimated model to show how the nature of monetary policymaking by the MPC changed over this period. They chart three distinct stages of transition: expansion from June 1997 to June 2003; the final pre-crisis stage of expansion to September 2006; and the crisis period to October 2011. Their results show an increasing influence of international developments and integration of the UK in the global economy. They also show how uncertainty and expectations of future inflation and output growth also had an increased effect on decision making in the crisis period compared with earlier periods. This is matched in their results with better network connections and influence of external members (non-Bank of England staff) on the MPC over the crisis period.

Bhattacharjee and Holly frame their analysis in terms of a two-equation model of inflation and output growth where the monetary authorities choose the interest rate to minimise an intertemporal loss function and that members of the MPC are assumed to follow, in their voting 
decisions, heterogeneous versions of the resulting interest rate rule because of factors such as differences in views of the state of the economy, varying beliefs about the size of parameters such as the effect of interest rates on inflation and the output gap and heterogeneity in the extent of and degree of uncertainty. On top of this, interactions between the members of the MPC are allowed to include differences in the extent to which individual members influence each other.

Using the voting records of individual MPC members from 1997 - 2011, the authors estimate individual decision rules conditioned on a range of variables including unemployment changes, the state of asset markets including housing, equity and foreign exchange markets, global GDP growth and US interest rates and the standard deviation of output growth. These reaction functions are allowed to differ across the three periods identified above. The estimates are then used to generate kernel density estimates of the implied cross-sectional distributions of response coefficients in the individual decision rules. Bhattacharjee and Holly present plots of the distributions for each response for each regime. The plots for the response of monetary policy to inflation expectations across the three regimes show MPC members were more concerned with inflation in the post-2004 period. Strikingly, increased uncertainty in output growth had a bigger impact on decision-making moving from earlier to later regimes. There is also evidence of increased heterogeneity in the output response over the regimes.

For each of the regimes in the above exercise a matrix of cross section interaction weights is estimated separately. This spatial matrix is then used to study network dynamics. The estimates show significant asymmetries in the influence each of the members of the MPC had on the voting behaviour of other members. Internal members of the committee (Bank of England staff) are shown to have had more influence than externals throughout; but the Governor is found not always to have been the most influential member. The network is shown to have been most well-connected during the crisis period and the external members more closely integrated into the network over that period.

\section{Chapter 8, "Nine votes, one view and not a hawk or dove in sight: the MPC during the Great}

Stability", by Richard Barwell (Royal Bank of Scotland), is unusual amongst the papers in this volume in that it originated as a discussant's response the previous chapter, by Bhattacharjee and Sean Holly. The editors were unanimous in their view that the evidence presented during the discussion was sufficiently persuasive to warrant expanding into a chapter in its own right.

Barwell takes a critical approach to the question of the nature of differences in opinion amongst the members of the MPC and the outcomes of the discussions in the MPC in terms of interest rate setting decisions. He shows that evidence of differences of view between MPC members is not reflected in differences in observed behaviour in the setting of interest rates. To assess differences in view, rather than focus on the MPC voting records or the minutes of MPC meetings, Barwell examines speeches made by members. His argument is that speeches contain the most complete public articulation of the views of members with a sufficient level of detail. The period of study is from the start of the MPC in 1997 to the author's estimate of the end of the long expansion from the perspective of the operation of the MPC in September 2007.

The chapter assembles evidence from speeches on a number of areas of concern for monetary policy over the period including: inflation expectations, globalisation, the operation of the labour market and structural issues in the corporate sector. These show a diversity of views on the nature and causes of developments in these areas and the likely consequences for the targets of monetary policy. Further evidence of differences in analysis by MPC members is shown in speeches referring to the behaviour of asset prices including house prices and the exchange rate as well as financial 
imbalances, household debt and the behaviour of money and credit in the aggregate. These differences also include how asset price bubbles might be addressed. It is shown that whilst the behaviour of output growth and price inflation over the period appears to be rather smooth, at the time a number of shocks arrived whose interpretation and likely consequence was not agreed on by members of the MPC as can be judged by their speeches. These differences in views are further shown to include differences in views on substantive issues such as the relative importance of the roles of data and underlying principles of economic analysis in reaching interest rate setting decisions.

The chapter argues that, in contrast to the views expressed in speeches, in terms of actual voting, disagreement amongst the members of the MPC was modest, when judged both by the relatively small number of individual dissenting votes and by the small size of the proposed changes in the interest rate which any dissenters proposed. Nearly all dissenting votes were at most 25 basis points away from the majority outcome. The question then is whether the size of this alternative setting for monetary policy would have been expected by the relevant MPC member to have had a significant effect on the economy. Barwell argues that it would be reasonable to assume that the impact of this difference was expected by them to be small, given the evidence from the Bank of England's economic models of the time, as provided to MPC members. Thus the outcome of the process of interest rate setting is shown to have produced much greater consensus in terms of the outcome than the evidence of differences in MPC members' views might suggest would have been the case.

The chapter then asks why there was such a consensus in voting, given the range of views uncovered in the speeches. Barwell assesses the role of agreement on the central projection for the economy in the future which is part of the MPC interest rate setting process and on the width of the fan charts which provide a measure of the degree of uncertainty surrounding the central projection. He suggests that the process that the MPC follows in agreeing on these items encourages the development of consensus. Attention is also drawn to the attitudes of MPC members to the significance of voting in dissent to the majority and the nature of consensus. Significance is also given to the nature of the economic models that the Bank supported at the time and the limited role for the modelling of financial flows that they incorporated which might have made promoting alternative views more difficult. The chapter concludes with proposals for reform of a number of features of the operation of the MPC to encourage the presentation and discussion of alternative views by MPC members. These reforms include the publication of the views of individual MPC members and development of a large suite of alternative economic models with different properties based on a range of views of how the economy works as well as greater resources being given to the assessment of alternative views and projections.

Inflation targeting in the UK did not take place in a vacuum. In chapter 9, "Emerging markets and import prices during the Long Expansion" by John Lewis and Jumana Saleheen (Bank of England), the authors start by noting the frequent claim that globalisation and the falling costs of transport and information contributed to the low-inflation experience of the developed world during the long expansion. Part of this was associated with the emergence of China as a major exporter of manufactured goods, due in part to its low wage costs. Substitution of purchases towards these lower priced goods had a direct effect on inflation; but the growth of competition also put pressure on domestic producers in the developed countries to reduce costs and/or substitute new technology for high-cost labour. These forces would have been likely to exert downward pressure on inflation in importing countries, including the United Kingdom.

The authors of this chapter perform a detailed study of UK trade data examining the impact on UK prices of import prices from specific groups of emerging economies. Emerging market exporters to 
the UK are collected into three main groups: China, the new members of the European Union from Eastern Europe, and other low wage emerging economies, such as Brazil and India. All three of these groups saw a rising market share of manufactured sales to the UK, but with the growth from China outstripping the others. In non-manufactured goods trade, however, it was the other low wage countries that saw the fastest growth of exports to the UK.

The empirical work reported in the paper uses a database of trade in around 3000 different products on an annual basis for the twelve years 1999-2011, where the information available includes prices and volumes of trade and the origin country. The authors test whether the growth of UK trade with these three market groups has put downward pressure on UK inflation, when other effects such as exchange rate changes are controlled for.

The authors find evidence that the growth in imports that substitutes for products from advanced economies has been associated with a reduction in import prices. They estimate that this switching to emerging-market-sourced goods reduced manufactured import price inflation by just under 0.9 percentage points per annum on average, and overall import price inflation by around 0.6 percentage points per annum. By far the biggest effect found was that coming from China in manufactured goods. There was, however, no evidence to support the hypothesis that higher inflation in emerging economies had spilled over into UK import prices.

Fiscal policy, and in particular fiscal retrenchment, played a crucial role in the macroeconomy as the Long Expansion ended, and rapidly became the Great Recession. In the final chapter of this volume, Chapter 10, "UK fiscal policy before the crisis", Paul Johnson (Institute of Fiscal Studies) provides an analysis of the development of fiscal policy during the Long Expansion, including some comparisons with earlier years. Despite the apparently historical unprecedented nature of the financial crisis, he shows that there was considerable similarity between the features of the path of fiscal policy from the late 1980s and the subsequent recession and that over the period of the long expansion and the recession following the financial crisis. Johnson asks what lessons might be learned from the conduct of fiscal policy over these years.

A great deal of the debate over the required size and length of fiscal retrenchment in Britain following the financial crisis turns on assessment of the fiscal position immediately prior to 2008. The overall fiscal position in the UK immediately prior to the financial crisis was a significant deficit: public sector net borrowing was $2.4 \%$ of national income. Assessing how significant this was depends, in part, on measuring the cyclical position of the economy at the time. Recent estimates suggest that structural borrowing might have been as high as $3.7 \%$ of national income due to the cyclical position of the economy at the time. The chapter shows these large deficit figures arose despite the introduction in 1997 of rules for the conduct of fiscal policy. The chapter examines first, the "golden rule" that over the business cycle government borrowing should only be for funding public investment and second, the sustainable investment rule that the national debt should not rise above $40 \%$ of GDP. Johnson asks whether the first was in practice open to manipulation and shows that the second was barely met immediately prior to the financial crisis. The analysis thus raises the question of whether more robust fiscal rules might be developed.

The overall fiscal position is the difference between two large numbers and so the question of sustainability is made very clear from examination of the paths of taxes and spending. Johnson shows that whilst both total tax revenue and spending show clear cyclical patterns, both also show the impact of policy choices over the period of the long expansion. Strikingly, spending on social 
security payments, which one might expect to most closely follow a cyclical pattern, followed a significantly upward path from the mid-1990s onwards despite the underlying positive growth in the economy and falling unemployment. Having shown that this increase was not due to payments related to an ageing population, Johnson suggests that these increases have not proved to be sustainable once the financial crisis arrived and output fell. On the taxation side the chapter shows that there were several discretionary changes to the overall taxation regime over recent years. As with the most recent experience with spending, significant tax cuts made in the late 1980s were subsequently undone in budgets in the early 1990s and 2000s following the failure of economic growth to be high enough to make the cost sustainable. Johnson also shows that taxation policy appears most obviously subject to a political or electoral cycle as taxes were raised in every budget following an election over the 30 years being examined. This post-election increase in taxes of an average $£ 7.5 \mathrm{bn}$ (in 2012/13 terms) has followed an average tax giveaway of $£ 2.2 \mathrm{bn}$ in the year before elections. In terms of sustainability, it is shown that revenue from North Seas oil taxation is expected to fall in the future whilst the dependence of corporation tax receipts on the financial sector appears to be less of a problem that their cyclicality. The chapter concludes with a call for future governments to introduce better fiscal rules which focus on longer term sustainability and to act with more caution and to resist calls for deviating from these rules.

\section{Concluding Remarks}

The papers collected here demonstrate both the complexity and inter-relatedness of a modern advanced economy, such as the UK, but also how hard it is to understand key risks in real time so that policy responses can be properly calibrated. It does seem clear now that it can no longer be tenable to think about any one arm of policy as sufficient to ensure an acceptable level of economic stability. Financial (including regulatory) policy, fiscal policy and monetary policy all play a fundamental role. As Andrew Crockett once put it: "The received wisdom is that risk increases in recessions and falls in booms. In contrast, it may be more helpful to think of risk as increasing during upswings, as financial imbalances build up, and materialising in recessions." ${ }^{4}$ That those risks were allowed to build up in a period that appeared to be one of stability does represent a first order policy error; but one that, even with the benefit of several years' hindsight, we still cannot fully understand. We hope that, if nothing else, the perspective and extended dialogue on the Long Expansion that this volume provides will mean that it will continue to be brought off the book shelves whenever people announce the end of boom and bust.

Alec Chrystal

Joe Pearlman

4 This point was made in a speech in 2000, "Marrying the micro- and macro-prudential dimensions of financial stability" 
Peter Smith

Stephen Wright

October 2014 